\title{
BMJ Anabolic steroids in patients Open undergoing total knee arthroplasty
}

\author{
David Metcalfe, ${ }^{1}$ Evan Watts, ${ }^{2}$ James P Masters, ${ }^{1}$ Neil Smith ${ }^{3}$
}

To cite: Metcalfe $D$, Watts $E$, Masters JP, et al. Anabolic steroids in patients undergoing total knee arthroplasty. BMJ Open 2012;2:e001435 doi:10.1136/bmjopen-2012001435

- Prepublication history and additional material for this paper are available online. To view these files please visit the journal online (http://dx. doi.org/10.1136/bmjopen2012-001435).

Received 7 May 2012 Accepted 24 August 2012

This final article is available for use under the terms of the Creative Commons Attribution Non-Commercial 2.0 Licence; see http://bmjopen.bmj.com

For numbered affiliations see end of article

\section{Correspondence to} Dr David Metcalfe; D.metcalfe@doctors.org.uk

\section{ABSTRACT}

Objectives: To systematically review the evidence for using anabolic-androgenic steroids (AAS) to aid rehabilitation following total knee replacement (TKR). Design: Systematic review of all clinical study designs.

Data sources: MEDLINE, EMBASE, AMED, CINAHL and the Cochrane Library were searched from inception to August 2012.

Eligibility criteria: All clinical study designs without language or patient demographic limits.

Outcome measures: All functional, physiological and administrative outcomes as well as reporting of adverse events.

Results: Only two small randomised controlled trials satisfied the inclusion criteria. Statistically significant improvements were reported in the AAS group for quadriceps strength at $3(p=0.02), 6(p=0.01)$ and 12 $(p=0.02)$ months, Functional Independence Measure score at 35 days $(p=<0.05)$ and Knee Society Score at 6 weeks $(p=0.02), 6$ months $(p=0.04)$ and 12 months $(p=0.03)$. However, differences in hamstring strength, bone mineral density, sit-to-stand testing, walking speed, length of hospital stay and need for further inpatient rehabilitation did not reach statistical significance. There were no reported adverse events.

Conclusions: There is insufficient evidence to recommend routine administration of AAS to patients undergoing TKR. However, pilot data suggest that AAS can be administered safely and may improve important postoperative outcome measures. This justifies a randomised trial sufficiently powered to identify between-group differences likely to be of clinical significance.

\section{BACKGROUND}

Total knee replacement (TKR) is a common treatment for end-stage knee osteoarthritis (OA). Joint replacement registries report increasing numbers of TKR operations, which are projected to rise by $673 \%$ to 3.48 million procedures in the USA alone by $2030 .^{1}$ Although TKR is safe and effective, ${ }^{2}{ }^{3}$ a significant number of patients experience continued functional limitation after surgery. ${ }^{4-6}$

\section{ARTICLE SUMMARY}

\section{Article focus}

- Does peri-operative anabolic steroid administration improve patient outcomes following total knee arthroplasty?

- Are peri-operative anabolic steroids associated with increased adverse effects?

\section{Key messages}

- There is insufficient trial data to recommend peri-operative anabolic steroids in patients undergoing total knee arthroplasty.

- Pilot studies suggest anabolic steroids can enhance recovery in these patients.

- A trial of greater power is necessary to confirm these findings and identify rare adverse events.

Strengths and limitations of this study

- The number of patients studied so far is very small and insufficient to guide practice.

- Trial heterogeneity prevented a meaningful meta-analysis.

Quadriceps weakness is common after TKR, even following extensive rehabilitation. ${ }^{7} 8$ Lower limb weakness is correlated with diminished functional performance, gait asymmetries and postural instability. ${ }^{9}$ A number of strategies have been used to mitigate lower limb muscle weakness, including lower-limb strengthening ${ }^{10}$ and neuromuscular electrical stimulation. ${ }^{11}{ }^{12}$ However, these techniques have only achieved modest improvements in rehabilitation post-TKR. ${ }^{10-12}$

Androgenic-anabolic steroids (AAS) are a potential means of reducing quadriceps weakness post-TKR. ${ }^{13}{ }^{14}$ They have been used successfully to treat other patient groups suffering from muscle atrophy, such as those with HIV/AIDS, ${ }^{15}$ renal failure, ${ }^{16}$ chronic obstructive pulmonary disease ${ }^{17}$ and muscle contusion injuries. ${ }^{18}$ AAS are a group of chemically related structures derived from the male sex hormone, testosterone. They are defined by their ability to promote muscle growth (anabolic properties) and masculinisation (androgenic properties). 
Evidence from athlete populations suggests AAS use can achieve significant increases in lean body mass and strength gains of up to $20 \% .{ }^{19}$ Although reportedly associated with a number of adverse effects, these anabolic properties raise the possibility of improving postoperative muscle weakness following TKR.

This review sought to evaluate the available evidence for using AAS in patients undergoing TKR.

\section{METHODS}

We devised a systematic review protocol according to the Preferred Reporting Items for Systematic Reviews and Meta-Analyses guidelines. ${ }^{20}$ The search strategy and eligibility criteria were determined in advance of implementation.

\section{Eligibility criteria}

All prospective and retrospective studies reporting the effects of AAS on physiological and functional outcomes after total knee arthroplasty were included. No language or patient demographic (eg, age and sex) limits were applied, although results were limited to studies of human participants. The predetermined outcomes were: 1. All functional outcomes, for example, walking speed, stairs, activities of daily living.

2. Relevant physiological outcomes, for example, muscle strength.

3. Length of hospital stay and need for inpatient rehabilitation.

4. Adverse effects.

\section{Study identification}

MEDLINE (1950-), EMBASE (1974-), AMED (1985-), CINAHL (1981-) and the Cochrane Library (1993-) were searched from inception to August 2012. Reference lists were used to identify any additional studies. The search strategy was:

knee replacement OR

knee arthroplasty AND

testosterone OR

anabolic steroids OR

anabolic-androgenic steroids

\section{Study selection}

Two reviewers independently screened titles and abstracts to identify studies meeting the inclusion criteria.

\section{Data extraction}

Two authors (DM and EW) independently extracted data from selected studies and there were no disagreements.

\section{RESULTS}

Five database entries were retrieved using the search strategy, of which only three were unique on elimination of duplicates. Only two (table 1) satisfied the inclusion criteria (figure 1), the third being a laboratory study. Both studies were small randomised controlled trials comparing peri-operative intramuscular testosterone against placebo in patients undergoing TKR.

As there was significant heterogeneity between the studies in terms of reported outcomes, data were not pooled and no statistical interpretation was attempted.

\section{Physiological outcomes}

Thigh strength

Hohmann et $a l^{14}$ assessed quadriceps and hamstring strength using peak torque measured with a Biodex Isokinetic Dynamometer. The groups improved steadily across both measures but recovery was accelerated in the AAS group. They found statistically significant differences in quadriceps strength between the groups at $3(\mathrm{p}=0.02)$, $6(p=0.01)$ and $12(p=0.02)$ months, although differences in hamstring strength were not statistically significant. The AAS group surpassed preoperative quadriceps strength by 3 months and hamstring torque by 6 months. In contrast, the control participants surpassed preoperative quadriceps strength by 6 months but did not regain preoperative hamstring strength within the 12-month study period.

\section{Bone mineral density}

Only Hohmann et $a l^{14}$ attempted to determine AAS impact on bone mineral density. Patients underwent DEXA scanning at the lumbar spine and neck of femur on the affected side 1 week preoperatively and 6 weeks postoperatively. No significant difference was

\begin{tabular}{|c|c|c|c|c|}
\hline Study & Study type & Participants & Intervention & Outcome measures \\
\hline $\begin{array}{l}\text { Hohmann } \\
\text { et } a l^{14}\end{array}$ & $\begin{array}{l}\text { Randomised, } \\
\text { double-blinded trial }\end{array}$ & $\begin{array}{l}10 \text { Participants. } \\
\text { Mean age } 65.7 \\
\text { (range } 58-72 \text { ) }\end{array}$ & $\begin{array}{l}50 \text { mg nandrolone decanoate } \\
\text { intramuscularly bi-weekly for } \\
6 \text { months }\end{array}$ & $\begin{array}{l}\text { Knee society score; isokinetic } \\
\text { strength testing; functional tests } \\
\text { (sit-to-stand, timed walk); bone } \\
\text { mineral density }\end{array}$ \\
\hline $\begin{array}{l}\text { Amory } \\
\text { et } a l^{13}\end{array}$ & $\begin{array}{l}\text { Randomised, } \\
\text { double-blinded trial }\end{array}$ & $\begin{array}{l}25 \text { Male } \\
\text { participants. Mean } \\
\text { age } 70 \\
\text { (range 58-86) }\end{array}$ & $\begin{array}{l}600 \text { mg testosterone enanthate } \\
\text { intramuscularly once weekly } \\
\text { for } 4 \text { weeks preoperatively }\end{array}$ & $\begin{array}{l}\text { Length of hospital stay; functional } \\
\text { tests }\end{array}$ \\
\hline
\end{tabular}


demonstrated between patients receiving AAS and control groups (percentage bone loss femur: AAS $0.71 \%$, control $-3.80 \%$; spine: AAS $-1.25 \%$, control $-1.97 \%)$.

\section{Biochemistry}

Amory et $a l^{13}$ measured serum total testosterone, renal function, lipoproteins, haematocrit, glutamic oxaloacetic transaminase and prostate-specific antigen at baseline and five weeks postoperatively. The AAS group showed a significant increase in serum total testosterone preoperatively from $12.5 \pm 4.5$ to $82.5 \pm 16.2 \mathrm{nmol} / \mathrm{l}$. Serum testosterone was not significantly different between the groups or when compared with baseline by 5 weeks postoperatively.

Haematocrit was significantly higher in the AAS group preoperatively $(\mathrm{p}=<0.05)$ but not postoperatively. There were no statistically significant differences observed in high-density lipoprotein, low-density lipoprotein or total cholesterol.

\section{Functional outcomes}

Sit-to-stand

Hohmann et $a l^{14}$ conducted a 'sit-to-stand' test modified from Bohannon ${ }^{21}$ preoperatively and at each follow-up appointment. Patients were invited to stand from a firm, armless chair with their arms crossed, then sit again. The AAS group showed improvement immediately postoperatively at the first (6 weeks) follow-up. In contrast, the control group did not regain preoperative speeds until 9 months. These findings were not statistically significant within the follow-up period $(\mathrm{p}=0.05)$.

\section{Timed walk}

The authors also assessed walking speed across a $10 \mathrm{~m}$ marked path and back. Averages of three trials at maximal speed were reported after an initial warm-up lap. They recorded little variation in walking speeds between the two groups and no statistically significant differences.

\section{Outcome scores}

Functional independence measure

Amory et $a l^{13}$ used the Functional Independence Measure (FIM) - a seven-point scale assessing ability to walk, stand and climb stairs-which was conducted by an investigator blinded to treatment. Both groups had similar preoperative FIM scores which fell postoperatively and neither returned to baseline by 35 days follow-up. However, by day three, participants in the AAS limb were significantly better at standing than the placebo group (FIM 5.2 vs $4.1, \mathrm{p}=<0.05$ ).

\section{Knee society score}

Hohmann et $a l^{14}$ used the Knee Society Score (KSS) and KSS function score. The former uses reported pain, flexion contracture, extension lag, flexion range, stability (anteroposterior and mediolateral) and alignment. There were significant differences in favour of the AAS group at 6 weeks $(p=0.02), 6$ months $(p=0.04)$ and 12 months $(\mathrm{p}=0.03)$. The KSS function score considers ability to walk, climb stairs and use of ambulatory aids. Although the authors reported trends towards greater improvement in the AAS, there were no statistically significant between group differences.

\section{Length of hospital stay}

Amory et al found that the AAS group had a shorter length of hospital stay $(5.9 \pm 2.4$ days) relative to the control group (6.7 \pm 2.5 days). Similarly, a smaller proportion of patients required inpatient rehabilitation (20\% vs $25 \%)$. However, these findings were not statistically significant.

\section{Adverse effects}

Neither study reported adverse events, side effects or mortality attributable to testosterone administration. In one study, ${ }^{13}$ an 81-year-old man from the AAS group died from known coronary artery disease 12 months postoperatively. Amory et al $l^{13}$ monitored renal and liver function as well as serum prostate-specific antigen and observed no differences.
Figure 1 Flow diagram showing inclusion and exclusion of items retrieved from a systematic literature search.

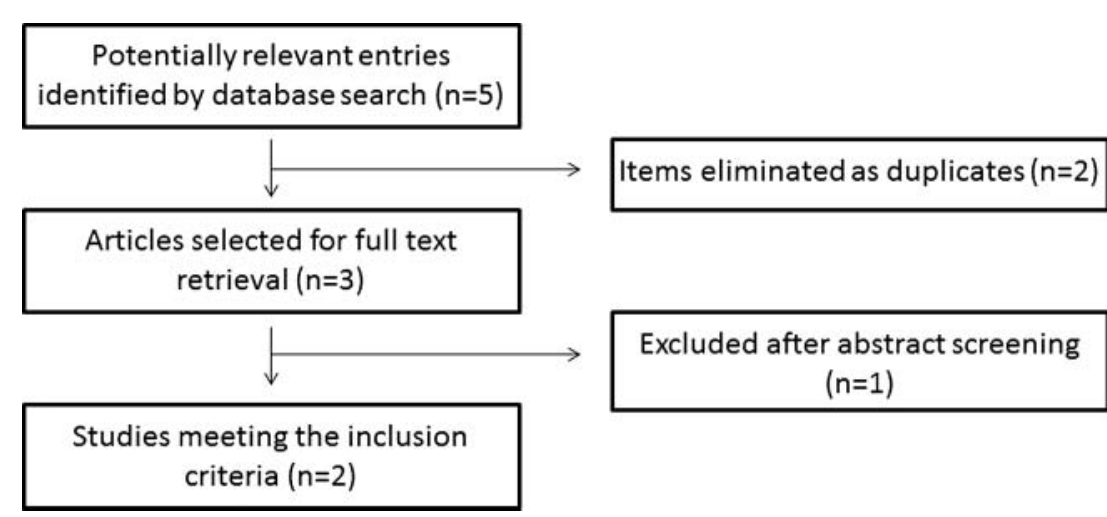




\section{DISCUSSION}

We identified a weak evidence base for use of AAS to improve functional and physiological outcomes post-TKR. However, both studies ${ }^{13}{ }^{14}$ reported trends towards improvement in their AAS cohorts across all measured outcomes, with the sole exception of timed walking speed. Across the two studies, AAS patients showed greater improvements in postoperative quadriceps and hamstring strength, bone mineral density and sit-to-stand testing. They also scored more highly on the FIM, KSS and KSS function score. AAS patients had a shorter length of hospital stay and less need for inpatient rehabilitation. A number of these observed differences were statistically significant, including quadriceps strength at all time points, standing as assessed by the FIM and KSS score. Between group differences on the sit-to-stand test at 9 months were almost statistically significant $(p=0.05)$. It is possible that other positive effects did not reach significance due to very small sample sizes. Interestingly, neither study reported that the placebo group surpassed the AAS cohort at any point on any of the outcomes tested.

Knee OA is accompanied by marked lower limb weakness which typically worsens after $\mathrm{TKR}^{22}$ Isometric flexion strength decreases by $17 \%$ in operated knees while no significant difference is measured on the contralateral side. ${ }^{23}$ These deficits persist long into the postoperative period. Operated knees attain hamstring peak torques comparable to the contralateral side after 12 months whereas quadriceps function is still limited two years later. ${ }^{24}$ Significant improvements have been reported with minimally invasive TKR techniques. For example, patients undergoing TKR using the mini-subvastus technique were found to match preoperative quadriceps strength after only 3 months. Quadriceps strength even surpassed preoperative levels by $17 \%$ at 6 and $30 \%$ at 12 months. ${ }^{25}$

Lower limb muscle strength is important as weakness is accompanied by worse functional outcomes. Both quadriceps and hip abductor strength are independently associated with improved ability to ascend and descend stairs. ${ }^{26}$ Quadriceps strength is also significantly correlated with walking speed. ${ }^{27}$ Both preoperative and postoperative quadriceps strength predicts improved functional performance one year after TKR. ${ }^{78}$

Attempts to improve lower limb muscle strength have achieved mixed success. Randomised trials comparing exercise training pre-TKR with usual care have reported improved lower limb strength, reduced pain and greater function postoperatively in the treated groups. ${ }^{28} 29 \mathrm{In}$ contrast, a Cochrane review of two prospective studies on postoperative neuromuscular stimulation reported no significant differences in quadriceps strength. ${ }^{12}$ A range of laboratory, animal and population studies on athletes have confirmed the ability of AAS to improve muscle strength. ${ }^{19}{ }^{30}$ The studies reported in this review support the potential for AAS to improve quadriceps strength and functional outcomes post-TKR. ${ }^{13} 14$
AAS can be administered through oral, buccal, intramuscular, subcutaneous or transdermal routes. However, they have been associated with a range of adverse effects. As many as $96 \%$ of regular AAS users report one or more objective side effects, commonly including acne, testicular atrophy, injection site pain, cutaneous striae and gynaecomastia. ${ }^{31}$ Serious adverse effects include hepatic, ${ }^{32}{ }^{33}$ cardiovascular $^{19}{ }^{34}$ and neuropsychiatric disease. ${ }^{35}{ }^{36}$ Long-term use may $^{3}$ stimulate myocardial hypertrophy with subsequent myocardial infarction, systolic dysfunction, arrhythmias and sudden death. ${ }^{37}{ }^{38}$ There is also a risk of dependence with $84 \%$ of athletes reporting withdrawal effects on AAS cessation and $57 \%$ satisfying DSM-III criteria for dependence. ${ }^{39}$

However, the safety profile is likely to differ between AAS use on physician advice and abuse. For example, bodybuilders use up to $6000 \mathrm{mg} /$ week testosterone, significantly higher than that administered by Amory et al (600 mg) or Hohmann et al (50 mg bi-weekly). Over half of bodybuilding users report sourcing AAS from underground laboratory facilities and $96 \%$ use other drugs concurrently, such as stimulants, fat loss agents and adjuvant anabolic compounds. ${ }^{40}$ For these reasons, it is important not to overstate the dangers of AAS use. ${ }^{41} 42$ Adverse effects are dose-related and largely reversible following cessation of use. ${ }^{434}$ This supports the finding by Amory et $a l^{13}$ that serum testosterone did not differ significantly between treated and placebo limbs at five weeks post-TKR. Importantly, researchers using AAS therapeutically in patient populations have not reported adverse effects. $^{13} 14-18$

The trials selected for this review suggest AAS could help mitigate quadriceps weakness post-TKR and improve functional outcomes. Early mobilisation and rehabilitation are known to shorten hospital length of stay, reduce cost and improve functional performance. ${ }^{45}$ In the absence of adverse effects reported in patient populations, AAS may provide another tool with which to expedite recovery after TKR. Although there is currently insufficient evidence to recommend the routine use of AAS, this preliminary evidence clearly justifies a randomised trial sufficiently powered to identify between-group differences likely to be of clinical significance.

Author affiliations

${ }^{1}$ Department of Orthopaedic Surgery, University Hospital Coventry and Warwickshire, Coventry, UK

${ }^{2}$ Division of Orthopaedic Surgery, University of Toronto, Ontario, Canada ${ }^{3}$ St George's University of London, London, UK

Contributors EW conceived the review and performed the initial literature search. DM drafted the manuscript in collaboration with EW and NS. JM made important critical revisions. All authors were involved in data analysis, writing and have approved the final draft.

Competing interests None.

Provenance and peer review Not commissioned; externally peer reviewed.

Data sharing statement No additional data are available. 


\section{REFERENCES}

1. Kurtz S, Ong K, Lau E, et al. Projections of primary and revision hip and knee arthroplasty in the United States from 2005 to 2030. $J$ Bone Joint Surg Am 2007;89:780-5.

2. Panel NC. (2004) NIH consensus statement on total knee replacement. J Bone Joint Surg Am 2003;86-A:1328-35.

3. Pavone V, Boettner F, Fickert S, et al. Total condylar knee arthroplasty: a long-term followup. Clin Orthop Relat Res 2001;388:18-25.

4. Finch E, Walsh M, Thomas SG, et al. Functional ability perceived by individuals following total knee arthroplasty compared to age-matched individuals without knee disability. J Orthop Sports Phys Ther 1998;27:255-63.

5. Walsh M, Woodhouse LJ, Thomas SG, et al. Physical impairments and functional limitations: a comparison of individuals 1 year after total knee arthroplasty with control subjects. Phys Ther 1998;78:248-58.

6. Franklin PD, Li W, Ayers DC. The Chitranjan Ranawat Award: functional outcome after total knee replacement varies with patient attributes. Clin Orthop Relat Res 2008;466:2597-604

7. Stevens JE, Mizner RL, Snyder-Mackler L. Quadriceps strength and volitional activation before and after total knee arthroplasty for osteoarthritis. J Orthop Res 2003;21:775-9.

8. Mizner RL, Petterson SC, Snyder-Mackler L. Quadriceps strength and the time course of functional recovery after total knee arthroplasty. J Orthop Sports Phys Ther 2005;35:424-36.

9. Moxley SD, Krebs DE, Harris BA. Quadriceps muscle strength and dynamic stability in elderly patients. Gait Posture 1999;10:10-20.

10. LaStayo PC, Meier W, Marcus RL, et al. Reversing muscle and mobility deficits 1 to 4 years after TKA: a pilot study. Clin Orthop Relat Res 2009;467:1493-500.

11. Stevens JE, Mizner RL, Snyder-Mackler L. Neuromuscular electrica stimulation for quadriceps muscle strengthening after bilateral total knee arthroplasty: a case series. J Orthop Sports Phys Ther 2004;34:21-9.

12. Monaghan B, Caulfield B, O'Mathúna DP. Surface neuromuscular electrical stimulation for quadriceps strengthening pre and post tota knee replacement. Cochrane Database Syst Rev 2010;1:CD007177.

13. Amory JK, Chansky HA, Chansky KL, et al. Preoperative supraphysiological testosterone in older men undergoing knee replacement surgery. J Am Geriatr Soc 2002;50:1698-701.

14. Hohmann E, Tetsworth K, Hohmann S, et al. Anabolic steroids after total knee arthroplasty. A double blinded prospective pilot study. J Orthop Surg Res 2010;5:93.

15. Strawford A, Barbieri T, Van Loan M, et al. Resistance exercise and supraphysiologic androgen therapy in eugonadal men with HIV-related weight loss. JAMA 1999;281:1282-90.

16. Johansen $\mathrm{KL}$, Mulligan K, Schambelan M. Anabolic effects of nandrolone decanoate in patients receiving dialysis. JAMA 1999;281:1275-81.

17. Ferreira IM, Verreschi IT, Nery LE, et al. The influence of 6 months of oral anabolic steroids on body mass and respiratory muscles in undernourished COPD patients. Chest 1998;114:19-28.

18. Beiner JM, Jokl $P$, Cholewicki J, et al. The effect of anabolic steroids and corticosteroids on healing of muscle contusion injury. $A m \mathrm{~J}$ Sports Med 1999;27:2-9.

19. Hartgens $F$, Kuipers $H$. Effects of androgenic-anabolic steroids in athletes. Sports Med 2004;34:513-54

20. Moherab D, Liberaticd A, Tetzlaffa J, et al. The PRISMA Group. Preferred reporting items for systematic reviews and meta-analyses: the PRISMA statement. Int J Surg 2010;8:336-41.

21. Bohannon RW. Sit-to-stand test for measuring performance of lower extremity muscles. Percept Mot Skills 1995;80:163-6.

22. Saleh KJ, Lee LW, Gandhi R, et al. Quadriceps strength in relation to total knee arthroplasty outcomes. Instr Course Lect 2010;59:119-30.
23. Lorentzen JS, Petersen MM, Brot $\mathrm{C}$, et al. Early changes in muscle strength after total knee arthroplasty. A 6-month follow-up of 30 knees. Acta Orthop Scand 1999;70:176-9.

24. Berman AT, Bosacco SJ, Israelite C. Evaluation of total knee arthroplasty using isokinetic testing. Clin Orthop Relat Res 1991;271:106-13.

25. Schroer WC, Diesfeld PJ, Reedy ME, et al. Isokinetic strength testing of minimally invasive total knee arthroplasty recovery. $J$ Arthroplasty 2010;25:274-9.

26. Piva SR, Teixeira PE, Almeida GJ, et al. Contribution of hip abducto strength to physical function in patients with total knee arthroplasty. Phys Ther 2011;91:225-33.

27. Yoshida Y, Mizner RL, Ramsey DK, et al. Examining outcomes from total knee arthroplasty and the relationship between quadriceps strength and knee function over time. Clin Biomech 2008;23:320-8.

28. Topp R, Swank AM, Quesada PM, et al. The effect of prehabilitation exercise on strength and functioning after total knee arthroplasty. PMR 2009;1:729-35

29. Swank AM, Kachelman JB, Bibeau W, et al. Prehabilitation before total knee arthroplasty increases strength and function in older adults with severe osteoarthritis. J Strength Cond Res 2011;25:318-25.

30. Sinha-Hikim I, Artaza J, Woodhouse L, et al. Testosterone-induced increase in muscle size in healthy young men is associated with muscle fiber hypertrophy. Am J Physiol Endocrinol Metab 2002;283: E154-64.

31. Evans NA. Current concepts in anabolic-androgenic steroids. $A m \mathrm{~J}$ Sports Med 2004;32:534-42.

32. Soe KL, Soe M, Gluud C. Liver pathology associated with the use of anabolic-androgenic steroids. Liver 1992;12:73-9.

33. Stimac D, Milic S, Dintinjana RD, et al. Androgenic/anabolic steroid-induced toxic hepatitis. J Clin Gastroenterol 2002;35:350-2.

34. Togna GI, Togna AR, Graziani M, et al. Testosterone and cocaine: vascular toxicity of their concomitant abuse. Thromb Res 2003;109:195-201.

35. Freinhar JP, Alvarez W. Androgen-induced hypomania. J Clin Psychiatry 1985;46:354-5.

36. Parssinen $\mathrm{M}$, Kujala $\mathrm{U}$, Vartiainen $\mathrm{E}$, et al. Increased premature mortality of competitive powerlifters suspected to have used anabolic agents. Int J Sports Med 2000;21:225-7.

37. D'Andrea A, Caso P, Salerno $G$, et al. Left ventricular early myocardial dysfunction after chronic misuse of anabolic-androgenic steroids: a Doppler myocardial and strain imaging analysis. $\mathrm{Br} \mathrm{J}$ Sports Med 2007;41:149-55.

38. Karila TA, Karjalainen JE, Mantysaari MJ, et al. Anabolic-androgenic steroids produce dose-dependant increase in left ventricular mass in power athletes, and this effect is potentiated by concomitant use of growth hormone. Int J Sports Med 2003;24:337-43.

39. Brower KJ, Blow FC, Young JP, et al. Symptoms and correlates of anabolic-androgenic steroid dependence. $\mathrm{Br} J$ Addict 1991;86:759-68.

40. Parkinson AB, Evans NA. Anabolic androgenic steroids: a survey of 500 users. Med Sci Sports Exerc 2006;38:644-51.

41. Berning JM, Adams KJ, Stamford BA. Anabolic steroid usage in athletics: facts, fiction, and public relations. J Strength Cond Res 2004;18:908-17.

42. Hoffman JR, Ratamess NA. Medical issues associated with anabolic steroid use: are they exaggerated? J Sport Sci Med 2006;5:182-93.

43. Dhar R, Stout CW, Link MS, et al. Cardiovascular toxicities of performanceenhancing substances in sports. Mayo Clin Proc 2005;80:1308-15

44. Schurmeyer T, Knuth UA, Belkien L, et al. Reversible azoospermia induced by the anabolic steroid 10-nortestosterone. Lancet 1984;25:417-20.

45. Munin MC, Rudy TE, Glynn NW, et al. Early inpatient rehabilitation after elective hip and knee arthroplasty. JAMA 1998;279:847-52. 